\title{
Improvement of exertional dyspnea and breathing pattern of inspiration to expiration after bronchial thermoplasty
}

Keisuke Miki* (10, Mari Miki, Kenji Yoshimura, Kazuyuki Tsujino, Hiroyuki Kagawa, Yohei Oshitani, Yuko Ohara, Yuki Hosono, Ryuya Edahiro, Hiroyuki Kurebe and Seigo Kitada

\begin{abstract}
Background: Bronchial thermoplasty (BT) is a bronchoscopic treatment that can ameliorate the symptoms of severe asthma. However, little is known about the mechanism by which BT improves exertional dyspnea without significantly changing the resting pulmonary function in asthmatics. To understand the mechanism, cardiopulmonary variables were investigated using cardiopulmonary exercise testing (CPET) in a patient with severe asthma before and after BT.

Case presentation: A 57-year-old Japanese man visited our hospital for consultation of the intractable asthma, which we managed with three treatment sessions of BT. Comparison of the findings pre-BT and at 1 year after BT demonstrated that (1) the resting tests for respiration showed no improvement in forced expiratory volume in $1 \mathrm{~s}$, but the forced oscillation technique showed decreases in both inhalation and exhalation respiratory resistance values, and (2) the CPET results showed (i) improvement in exertional dyspnea, exercise endurance, and arterial oxygen saturation at the end of exercise; (ii) that the expiratory tidal volume exceeded the inspiratory tidal volume during exercise, which implied that a sufficient exhalation enabled longer inspiratory time and adequate oxygen absorption; and (iii) that an increase in respiratory frequency could be prevented throughout exercise.
\end{abstract}

Conclusions: This case report described a novel mechanism of BT in improving exertional dyspnea and exercise duration, which was brought about by ventilatory improvements related to the breathing pattern of inspiration to expiration.

Keywords: Asthma, Cardiopulmonary exercise testing, Dynamic hyperinflation, Ventilation

\section{Case presentation}

A 57-year-old Japanese man visited our hospital for consultation of asthma attacks with exertional dyspnea. When he was about 30 years old, he was started on asthma treatment by a local physician. However, the asthma attacks occurred frequently despite triple therapy with high-dose inhaled corticosteroids, inhaled long-acting beta- 2 agonist drugs, and long-acting anticholinergic drugs. He had no history of smoking. Blood test findings showed $7.1 \%$ eosinophilia $(460 / \mu \mathrm{L})$ and an elevated total IgE level at $256 \mathrm{IU} / \mathrm{mL}$ (specific IgE for house dust:

*Correspondence: mikisuke@toneyama.go.jp

Department of Respiratory Medicine, National Hospital Organization

Toneyama National Hospital, 5-1-1 Toneyama, Toyonaka, Osaka 560-8552, Japan
$0.97 \mathrm{U}_{\mathrm{A}} / \mathrm{mL}$; for mite: $1.18 \mathrm{U}_{\mathrm{A}} / \mathrm{mL}$ ). There was bronchial wall thickening on both lungs on plain computed tomography of the chest. Exhaled nitric oxide concentration was increased at $68 \mathrm{ppb}$. After managing the asthma attack with oral intake of prednisolone at $30 \mathrm{mg} /$ day for 6 days, there was persistence of dyspnea and fluctuations in forced expiratory volume in one second $\left(\mathrm{FEV}_{1}\right)$ values from $1.17 \mathrm{~L}$ before steroid treatment to $2.33 \mathrm{~L}$ after steroid treatment. The patient was diagnosed as intractable asthma based on his history and the clinical course. Using the Alair Bronchial Thermoplasty (BT) System (Boston Scientific Corporation, MA, USA), BT was performed in three treatment sessions with a different region of the lung. Each treatment was performed approximately 3 weeks apart. Because the stenosis was observed in each 
lobe bronchus due to bronchial mucosal thickening, total sessions consisted of 98 activations. At 1 year after BT, the resting tests for respiration showed no improvement in $\mathrm{FEV}_{1}$, but the forced oscillation technique (FOT) $[1,2]$ (MostGraph, Chest M.I., Tokyo, Japan) showed decreases in both inhalation and exhalation respiratory resistance values (Table 1 and Fig. 1). Assessment of asthma control scores [3] showed improvement from 19 before BT to 25 at 1 year after BT. CPET (Aero monitor AE310S, Minato Medical Science Co., Ltd., Osaka, Japan) was performed using a similar treadmill protocol by Sheffield [4]. All Table 1 Changes in resting pulmonary function
and forced oscillatory parameters after BT

\begin{tabular}{|c|c|c|c|}
\hline & Pre-BT & $\begin{array}{l}3 \text { months } \\
\text { after BT }\end{array}$ & 1 year after BT \\
\hline \multicolumn{4}{|l|}{ Pulmonary function test } \\
\hline $\mathrm{FEV}_{1}, \mathrm{~L}$ & 2.63 & 2.52 & 2.38 \\
\hline$\% \mathrm{FEV}_{1}, \%$ predicted & 76.2 & 74.3 & 70.8 \\
\hline $\mathrm{FEV}_{1} / \mathrm{FVC}_{1} \%$ & 51.2 & 47.4 & 46.5 \\
\hline$V C, L$ & 5.10 & 5.21 & 5.17 \\
\hline$I C, L$ & 3.38 & 3.51 & 3.23 \\
\hline \multicolumn{4}{|c|}{ Forced oscillation technique } \\
\hline $\mathrm{R} 5 \mathrm{ex}, \mathrm{cmH}_{2} \mathrm{O} / \mathrm{L} / \mathrm{s}$ & 3.83 & 3.65 & 2.42 \\
\hline $\mathrm{R} 5 \mathrm{in}, \mathrm{CmH}_{2} \mathrm{O} / \mathrm{L} / \mathrm{s}$ & 1.96 & 2.12 & 1.66 \\
\hline $\mathrm{R} 20 \mathrm{ex}, \mathrm{cmH}_{2} \mathrm{O} / \mathrm{L} / \mathrm{s}$ & 2.77 & 2.68 & 2.03 \\
\hline $\mathrm{R} 2 \mathrm{O}$ in, $\mathrm{cmH}_{2} \mathrm{O} / \mathrm{L} / \mathrm{s}$ & 1.80 & 2.12 & 1.68 \\
\hline Fres ex, Hz & 9.48 & 10.56 & 8.07 \\
\hline Fres in, $\mathrm{Hz}$ & 7.41 & 8.67 & 7.19 \\
\hline
\end{tabular}

$B T$ bronchial thermoplasty, ex expiratory, $F E V_{1}$ forced expiratory volume in $1 \mathrm{~s}$, Fres resonant frequency, FVC forced vital capacity, IC inspiratory capacity, in inspiratory, $R 5$ the resistance at $5 \mathrm{~Hz}, R 20$ the resistance at $20 \mathrm{~Hz}, V C$ vital capacity the CPET results indicated that exercise was terminated when the target heart rate (THR), which was calculated as 220-age in years was reached; thereafter, the CPET results were evaluated (Table 2, Fig. 2). At the end of exercise, comparison of the findings at pre-BT and at 1 year after BT showed (1) improvement in dyspnea based on the Borg scale; (2) longer exercise time to reach the THR; and (3) increase in arterial oxygen saturation $\left(\mathrm{SpO}_{2}\right)$.

\section{Discussion}

This case report described improvements in the exertional breathing pattern as the novel mechanism by which BT improved exertional dyspnea in a patient with intractable asthma. BT is a bronchoscopic treatment that can ameliorate the subjective symptoms of severe bronchial asthma that is difficult to control [5-9]. In the future, $\mathrm{BT}$ is expected to be one of the treatment strategies for severe asthma. However, the mechanisms by which BT improves the subjective symptoms of asthma without significantly changing the resting pulmonary function $[6,8]$ are yet to be elucidated. Exertional dyspnea is a common symptom in asthma, and the mechanisms of it in asthma are complex [10]. In the present case, we focused on the pattern of exertional ventilation because minute ventilation $\left(\dot{\mathrm{V}}_{\mathrm{E}}\right)$ decreased during exercise after BT (Fig. 2a). Although not all asthmatics develop dynamic hyperinflation (DH) [10], before BT in this case, the patient presented with $\mathrm{DH}$ during mid-exercise at pre-BT, because, based on the finding that the expiratory tidal volume $\left(\mathrm{V}_{\mathrm{Tex}}\right)$ reached a plateau followed by a sharp increase in respiratory frequency $\left(f_{R}\right)$. At 1 year after BT, the breathing pattern of DH improved (Fig. 2b, c). Similarly, a study by Thomen et al. [11] used a combination of helium 3 ,

\section{Pre-BT}

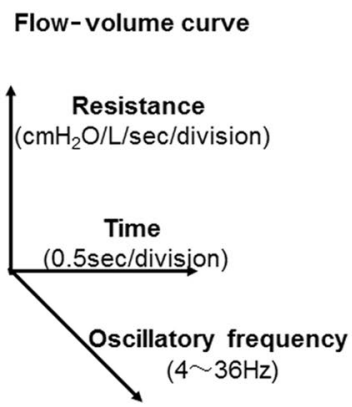

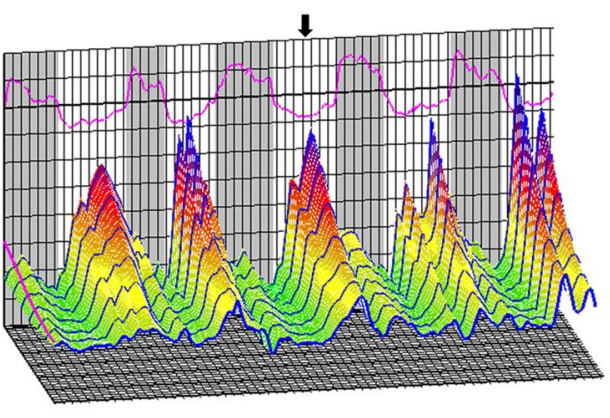

1 year after BT

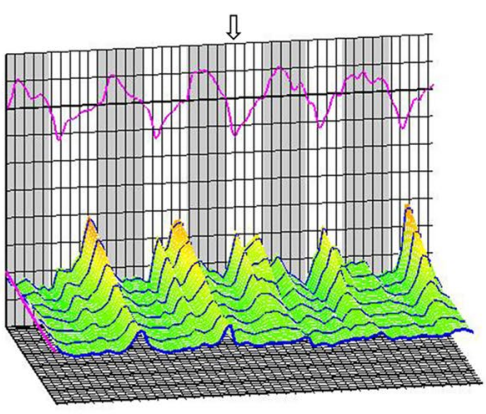

Fig. 1 Changes in the resting respiratory system resistance on the flow-volume curve at pre-BT and at 1 year after BT. The forced oscillation technique was used. Pre-BT, a semicircular flow-volume curve was detected in the expiratory phase (white zone), with the nadir (closed arrow) detected in the middle of the phase. At 1 year after BT, the flow-volume curve was changed to a triangular shape, with the nadir (open arrow) detected in the early expiratory phase. The gray zone represents the inspiratory phase. BT bronchial thermoplasty 
Table 2 Post-BT changes in cardiopulmonary function assessed at THR during CPET

\begin{tabular}{|c|c|c|c|}
\hline & Pre-BT & $\begin{array}{l}3 \text { months } \\
\text { after BT }\end{array}$ & 1 year after BT \\
\hline Dyspnea, Borg scale & 7 & 4 & 4 \\
\hline HR response, \% & 105 & 109 & 103 \\
\hline Exercise time, min & 9.6 & 14.5 & 15.5 \\
\hline$\dot{\mathrm{V}}_{\mathrm{O}_{2}}, \mathrm{~mL} \min ^{-1} \mathrm{~kg}^{-1}$ & 26.0 & 25.7 & 25.0 \\
\hline$\dot{V}_{E}, L \min ^{-1}$ & 79.4 & 75.4 & 75.3 \\
\hline$\Delta \mathrm{FO}_{2}, \%$ & 2.97 & 3.09 & 3.04 \\
\hline $\mathrm{V}_{\text {Tex, }}, \mathrm{mL}$ & 2412 & 2495 & 2559 \\
\hline $\mathrm{V}_{\mathrm{T}}$ in $-\mathrm{V}_{\text {Tex }}, \mathrm{mL}$ & 6 & 23 & -64 \\
\hline $\mathrm{f}_{\mathrm{R}^{\prime}}$ breaths $\min ^{-1}$ & 32.9 & 30.2 & 29.4 \\
\hline $\mathrm{Ti} / \mathrm{Ttot}$ & 0.39 & 0.37 & 0.39 \\
\hline $\mathrm{V}_{\mathrm{D}} \mathrm{N}_{\mathrm{Tex}}$ & 0.28 & 0.28 & 0.27 \\
\hline$\dot{\mathrm{V}}_{\mathrm{E}} \dot{\mathrm{V}}_{\mathrm{O}_{2}}$ & 41 & 41 & 41 \\
\hline$\dot{\mathrm{V}}_{\mathrm{E}} / \dot{\mathrm{V}}_{\mathrm{CO}_{2}}$ & 38 & 35 & 36 \\
\hline $\mathrm{SpO}_{2}, \%$ & 91 & 96 & 94 \\
\hline AT, $\mathrm{mL} \min ^{-1}$ & 1147 & 1277 & 1230 \\
\hline
\end{tabular}

$A T$ anaerobic threshold obtained by the $\mathrm{V}$-slope method, $B T$ bronchial thermoplasty, CPET cardiopulmonary function testing, $\triangle \mathrm{FO}_{2}$ the inspired oxygen concentration $\left(\mathrm{FiO}_{2}\right)$ minus the expired oxygen concentration $\left(\mathrm{FeO}_{2}\right)$, ex expiratory, $f_{R}$ breathing frequency, $H R$ heart rate, in inspiratory, $\mathrm{SpO}_{2}$ oxygen saturation, Ti/Ttot the ratio of inspiratory time to total breathing cycle time, $T H R$ target heart rate $=220$ - age (years), $\dot{V}_{\mathrm{CO}_{2}}$ carbon dioxide output, $V_{D} V_{\text {Tex }}$ physiologic dead space/tidal volume ratio, $\dot{V}_{E}$ minute ventilation, $\dot{V}_{\mathrm{O}_{2}}$ oxygen uptake, $V_{T}$ tidal volume

magnetic resonance imaging, and $\mathrm{CT}$ to demonstrate that after BT, the ventilation defects decreased with time.

Although improvement of $\mathrm{DH}$ was important, the reduced $\dot{V}_{E}$ requirement throughout exercise and the prolonged exercise time obtained in the present case were noteworthy (Fig. 2a and Table 2). Considering that both $V_{T e x}$ and $f_{R}$ during exercise were reduced after $B T$ (Fig. 2b, c), exertional dyspnea, especially during midexercise, may have pathophysiologic mechanisms other than the occurrence of $\mathrm{DH}$ only in the late exercise phase. $\mathrm{V}_{\text {Tex }}$ exceeded inspiratory tidal volume $\left(\mathrm{V}_{\text {Tin }}\right)$ form resting to peak exercise, especially at 1 year after BT (Fig. 2d). This implied that the patient could exhale sufficiently after BT, which improved both the static and dynamic hyperinflation throughout exercise. Furthermore, mean expiratory flow ( $\mathrm{V}_{\mathrm{Tex}} /$ expiratory time: $\mathrm{Te}$ ) was reduced throughout exercise (Fig. 2e). We deduced that the obtained ventilation pattern at 1 year after BT might be related to the decrease in respiratory resistance during expiration (Table 1 and Fig. 1), and may have been affected by a reduction in the airway smooth muscle by BT, as demonstrated in multiple studies [12]. After BT, the sufficient exhalation obtained increased the time for inhalation, as shown by the increase in the inspiratory duty cycle (Ti/Ttot) (Fig. 2f) from resting to peak exercise, and shortened the time for the expiratory flow-volume curve to reach a nadir (Fig. 1). In general, the $\mathrm{Ti} /$ Ttot at rest is lower in asthmatics than in normal subjects [13, 14]; however, the exertional relationship between Ti/Ttot and dyspnea has not been studied completely. On the other hand, in patients with chronic obstructive pulmonary disease, we have confirmed that under similar ventilation conditions during exercise, the ability to absorb oxygen was higher when the Ti/Ttot increased than when the Ti/Ttot decreased [15]. Therefore, the increase in the ventilation equivalent for oxygen was suppressed during the late exercise phase (Fig. 2g); this implied that adequate ventilatory efficiency to absorb oxygen was obtained after BT. Laveneziana et al. [16] reported that the predominant exertional symptom in asthmatics was increased inspiratory effort, rather than expiratory effort, regardless of the presence of DH. Given the report, after BT in the present case, the longer inspiration time obtained by exhalation of enough trapped air may have led to effective and effortless pattern of breathing and reduction of the asthmatic symptoms during exercise (Fig. 2h).

There were some limitations of the present case study. First, although FOT might not be universally accepted, detailed analyses, including bronchial challenge test, should have been performed to confirm the presence of bronchial responsiveness before and after BT. Second, monoclonal antibody treatment prior to invasive BT should have been indicated in the present patient. However, in the light of the cost of prolonged asthma therapy [17], BT was chosen instead monoclonal antibody treatment for the present case. BT could become costly and therapeutically effective, if the mechanisms by which BT improves the symptoms of asthma are elucidated and if the patients who can respond to BT are identified.

\section{Conclusions}

In the present case, BT did not improve the resting pulmonary function. However, after $\mathrm{BT}, \mathrm{V}_{\mathrm{Tex}}$ exceeded $\mathrm{V}_{\mathrm{Tin}}$ form resting to peak exercise, which implied that a sufficient exhalation enabled longer inspiratory time, i.e., the higher Ti/Ttot, and the required $\dot{\mathrm{V}}_{\mathrm{E}}$ was reduced throughout exercise. Exertional dyspnea and exercise duration were primarily improved by obtaining better breathing patterns. Based on these, the capability of CPET to quantify the treatment effect demonstrated that breathing pattern may be an important mechanism of exertional dyspnea in asthmatics, which in turn might become a better predictor of response to BT. Further analyses, and lager studies are required to elucidate the clinical effectiveness of BT, with focus on breathing pattern in asthmatics. 


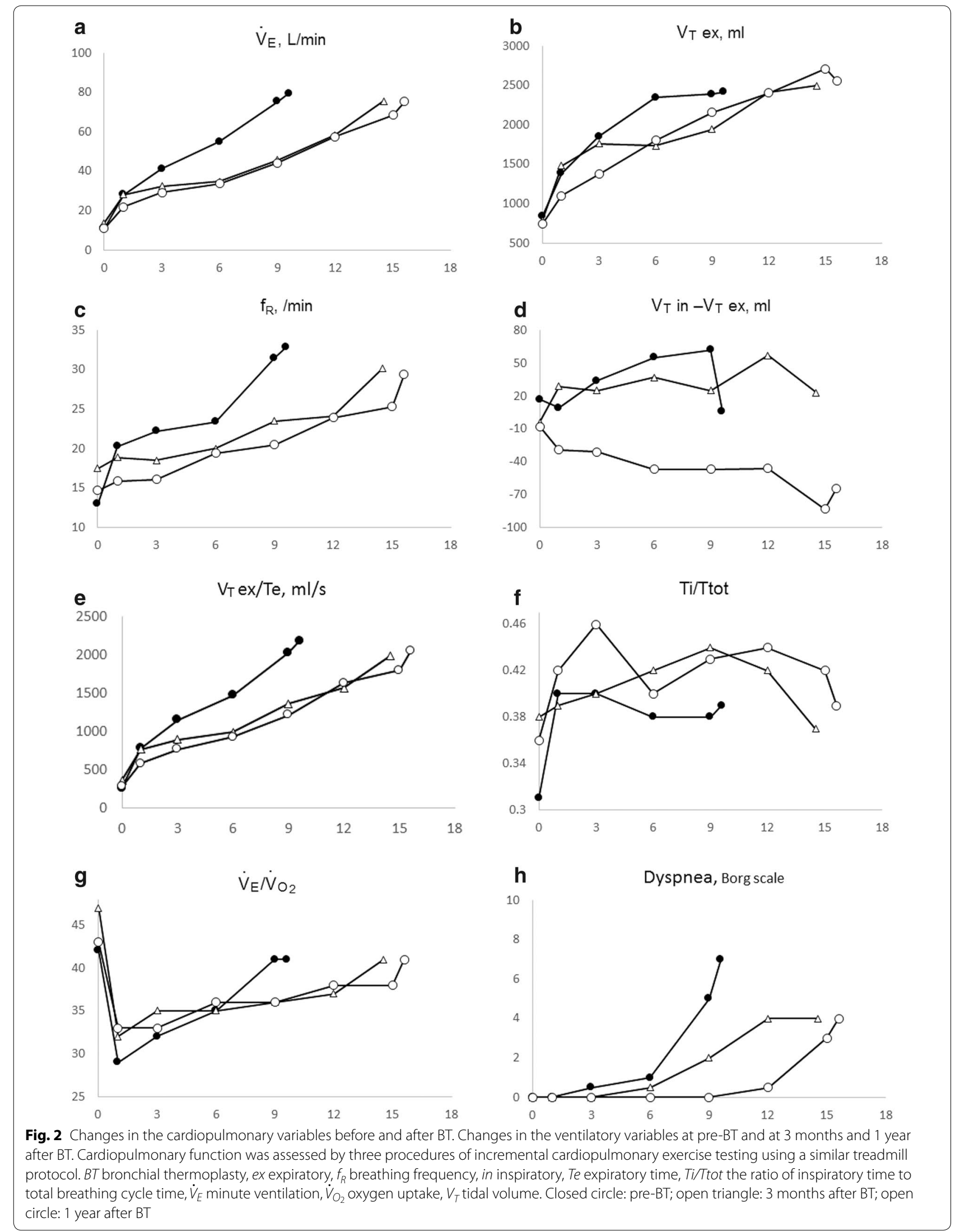




\section{Authors' contributions}

All authors performed experiments, and were involved in the clinical management of the patient. KM drafted the initial manuscript. All authors contributed to the manuscript writing and approved the submission of the final manuscript. Correspondence should be addressed to KM. All authors read and approved the final manuscript.

\section{Acknowledgements}

The authors would like to thank Ms. S. Ito and Ms. S. Sakaguchi for their help on the CPET measurements.

\section{Competing interests}

The authors declare that they have no competing interests.

\section{Availability of data and materials}

This case report does not include any clinical dataset to be shared. The datasets used and/or analyzed during the current case study are available from the corresponding author on reasonable request.

\section{Consent for publication}

Not applicable.

\section{Ethics approval and consent to participate}

The Ethics Board of National Hospital Organization Toneyama National Hospital (Approval Number, 1713). Written informed consent was obtained from the patient (in Japanese).

\section{Funding}

None.

\section{Publisher's Note}

Springer Nature remains neutral with regard to jurisdictional claims in published maps and institutional affiliations.

Received: 6 April 2018 Accepted: 23 July 2018

Published online: 29 October 2018

\section{References}

1. Oostveen E, MacLeod D, Lorino H, Farre R, Hantos Z, Desager K, Marchal F. The forced oscillation technique in clinical practice: methodology, recommendations and future developments. Eur Respir J. 2003;22(6):1026-41.

2. Shirai T, Kurosawa H. Clinical application of the forced oscillation technique. Intern Med (Tokyo, Japan). 2016;55(6):559-66.

3. Nathan RA, Sorkness CA, Kosinski M, Schatz M, Li JT, Marcus P, Murray $J$ J, Pendergraft TB. Development of the asthma control test: a survey for assessing asthma control. J Allergy Clin Immunol. 2004;113(1):59-65.

4. Miki K, Maekura R, Hiraga T, Hashimoto H, Kitada S, Miki M, Yoshimura K, Tateishi Y, Fushitani K, Motone M. Acidosis and raised norepinephrine levels are associated with exercise dyspnoea in idiopathic pulmonary fibrosis. Respirology (Carlton, Vic). 2009;14(7):1020-6.

5. Castro M, Rubin AS, Laviolette M, Fiterman J, De Andrade Lima M, Shah PL, Fiss E, Olivenstein R, Thomson NC, Niven RM, et al. Effectiveness and safety of bronchial thermoplasty in the treatment of severe asthma: a multicenter, randomized, double-blind, sham-controlled clinical trial. Am J Respir Crit Care Med. 2010;181(2):116-24.

6. Chupp G, Laviolette M, Cohn L, McEvoy C, Bansal S, Shifren A, Khatri S, Grubb GM, McMullen E, Strauven R, et al. Long-term outcomes of bronchial thermoplasty in subjects with severe asthma: a comparison of 3-year follow-up results from two prospective multicentre studies. Eur Respir J. 2017;50(2):1700017. https://doi.org/10.1183/13993003.00017 $-2017$.

7. Cox G, Thomson NC, Rubin AS, Niven RM, Corris PA, Siersted HC, Olivenstein R, Pavord ID, McCormack D, Chaudhuri R, et al. Asthma control during the year after bronchial thermoplasty. N Engl J Med. 2007;356(13):1327-37.

8. Laxmanan B, Egressy K, Murgu SD, White SR, Hogarth DK. Advances in bronchial thermoplasty. Chest. 2016;150(3):694-704.

9. Pavord ID, Cox G, Thomson NC, Rubin AS, Corris PA, Niven RM, Chung KF, Laviolette M. Safety and efficacy of bronchial thermoplasty in symptomatic, severe asthma. Am J Respir Crit Care Med. 2007;176(12):1185-91.

10. Weatherald J, Lougheed MD, Taille C, Garcia G. Mechanisms, measurement and management of exertional dyspnoea in asthma: number 5 in the series "Exertional dyspnoea" edited by Pierantonio Laveneziana and Piergiuseppe Agostoni. Eur Respir Rev. 2017;26(144):170015. https://doi. org/10.1183/16000617.0015-2017.

11. Thomen RP, Sheshadri A, Quirk JD, Kozlowski J, Ellison HD, Szczesniak $\mathrm{RD}$, Castro M, Woods JC. Regional ventilation changes in severe asthma after bronchial thermoplasty with (3)He MR imaging and CT. Radiology. 2015:274(1):250-9.

12. d'Hooghe JNS, Ten Hacken NHT, Weersink EJM, Sterk PJ, Annema JT, Bonta $\mathrm{PI}$. Emerging understanding of the mechanism of action of bronchial thermoplasty in asthma. Pharmacol Ther. 2018;181:101-7.

13. Neder JA, Dal Corso S, Malaguti C, Reis S, De Fuccio MB, Schmidt H, Fuld $J P$, Nery LE. The pattern and timing of breathing during incremental exercise: a normative study. Eur Respir J. 2003;21(3):530-8.

14. Tobin MJ, Chadha TS, Jenouri G, Birch SJ, Gazeroglu HB, Sackner MA Breathing patterns. 2. Diseased subjects. Chest. 1983;84(3):286-94.

15. Miki K, Tsujino K, Edahiro R, Kitada S, Miki M, Yoshimura K, Kagawa H, Oshitani Y, Ohara Y, Hosono Y, et al. Exercise tolerance and balance of inspiratory-to-expiratory muscle strength in relation to breathing timing in patients with chronic obstructive pulmonary disease. J Breath Res. 2018. https://doi.org/10.1088/1752-7163/aaa6db.

16. Laveneziana P, Lotti P, Coli C, Binazzi B, Chiti L, Stendardi L, Duranti R, Scano G. Mechanisms of dyspnoea and its language in patients with asthma. Eur Respir J. 2006;27(4):742-7.

17. Zafari Z, Sadatsafavi M, Marra CA, Chen W, FitzGerald JM. Cost-effectiveness of bronchial thermoplasty, omalizumab, and standard therapy for moderate-to-severe allergic asthma. PLoS ONE. 2016;11(1):e0146003.

Ready to submit your research? Choose BMC and benefit from

- fast, convenient online submission

- thorough peer review by experienced researchers in your field

- rapid publication on acceptance

- support for research data, including large and complex data types

- gold Open Access which fosters wider collaboration and increased citations

- maximum visibility for your research: over 100M website views per year

At BMC, research is always in progress.

Learn more biomedcentral.com/submissions 